\title{
PENGARUH MOTEDE FERNALD TERHADAP KEMAMPUAN MEMBACA PEMAHAMAN PADA MATA PELAJARAN BAHASA INDONESIA KELAS IV SEKOLAH DASAR
}

\author{
Ragil Pratiwi, Yosi Wulandari \\ Universitas Ahmad Dahlan \\ Ragilpratiwi41@gmail.com
}

\begin{abstract}
This research aims to find out the influence of the Fernald method on the ability to read class IV learners on Indonesian subjects at the elementary School of Golo Yogyakarta. This method of research using Quasi-Experimental Design research with the design used is Nonequivalent Control Group Design. The population in this study was the students of class IV Elementary school year Golo school 2018/2019 consisting of 2 classes, namely IV A class and IV B class with a total of 53 students with a sample class of IVA and IVB classes having the ability in cognitive aspects Relatively the same. Sampling techniques, i.e. the respondents who are members of the sample. The existing research variables 2 are independent variables (variable-free) and dependent variables (variable bound). The data collection techniques in this research use test instruments that have tested validation and its rehabilitation, and also use documentation and observation. Data analysis techniques used are preceded by a test of normality and homogeneity. This result is that Recount 0.711 is larger than the table is said to be valid because it is more value (0.444). The test of the realities of 23 questions over (0.6) example 0.952 means a rebel can research. It is shown to determine the hypothesis that is Thing > this using independent test sample test with the value of SIG 0.200 this data is Normal due to more than 0.05 data for IVA and IVB classes. The value of SIG. (2tailed) 0.000 is of influence. So there is an influence on the ability to read understanding at SD Negeri Golo Yogyakarta. Conclusion of Fernald's method can increase the prestige of students ' ability to read understanding Bahasa Indonesia in Class IV Elementary School of Golo Yogyakarta.
\end{abstract}

Keywords: method fernald, indonesian language, reading comprehension skills

\begin{abstract}
ABSTRAK
Penelitian ini bertujuan mengetahui mendeksripsi pengaruh metode fernald terhadap kemampuan membaca peserta didik kelas IV pada mata pelajaran Bahasa Indonesia di SD Negeri Golo Yogyakarta. Metode penelitian ini menggunakan penelitian Quasi Expreimental Design dengan desain yang digunakan adalah Nonequivalent Control Group Design. Populasi dalam penelitian ini adalah peserta didik kelas IV SD Negeri Golo tahun ajaran 2018/2019 yang terdiri 2 kelas, yaitu kelas IV A dan kelas IV B dengan jumlah 53 peserta didik dengan Sampel kelas IVA dan kelas IVB memiliki kemampuan dalam aspek kognitif yang relatif sama. pengambilan sampel menggunakan teknik purposive sampling, yaitu responden yang menjadi anggota sampel. Variabel penelitian ada 2 yaitu variabel independent (variabel bebas) dan variabel dependet (variabel terikat). Teknik pengumpulan data dalam penelitian ini menggunakan instrument tes yang telah diuji validasi dan reabilitasnya, dan juga menggunakan
\end{abstract}


dokumentasi dan Observasi. Teknik analisis data menggunakan yang didahului dengan uji normalitas dan Homogenitas. Hasil ini yaitu terdapat Rhitung 0,711 lebih besar dari pada $\mathrm{R}_{\text {tabel }}$ dikatakan valid karena lebih nilai $(0,444)$. Uji realibitas dari 23 pertanyaan lebih dari $(0,6)$ contoh 0,952 berarti reabel bisa penelitian. Hal ini ditunjukkan untuk menentukan hipotesis yaitu Thitung $>T_{\text {tabel }}$ menggunakan uji independent sampel test dengan nilai sig 0,200 data ini Normal karena data lebih dari 0,05 untuk kelas IVA dan IVB. Nilai sig.(2-tailed) 0,000 adanya pengaruh. Sehingga terdapat ada pengaruh tingkat kemampuan membaca pemahaman di SD Negeri Golo Yogyakarta. Kesimpulan metode Fernald dapat meningkatkan prestasti peserta didik kemampuan membaca pemahaman Bahasa Indonesia di kelas IV SD Negeri Golo Yogyakarta

Kata kunci: Metode Fernald., Bahasa Indonesia, Kemampuan Membaca Pemahaman

\section{PENDAHULUAN}

Pendidikan merupakan suatu proses yang dapat membantu manusia dalam mengembangkan potensi yang dimilikinya sehingga dapat menghadapi segala tantangan dan perubahan dimasa yang akan datang, Pendidikan adalah hal yang sangat penting dalam membentuk kepribadian manusia Menurut UU No. 20 Tahun 2003 tentang Sistem Pendidikan Nasional yaitu: Pendidikan adalah usaha sadar dan terencana untuk mewujudkan suasana belajar dan proses pembelajaran agar peserta didik secara aktif mengembangkan potensi dirinya untuk memiliki kekuatan spritual keagamaan, pengendalian diri, kepribadian, kecerdasan, akhlak mulia, serta keterampilan yang diperlukan dirinya, masyarakat, bangsa dan negara. Hal ini membuktikan bahwa pembelajaran Bahasa Indonesia sangat penting bagi Peserta didik kelas IV SD Negeri Golo, dengan pengetahuan Bahasa Indonesia yang didapat, Peserta didik diharapkan dapat membaca pemahaman. Pengajaran membaca tersebut dapat menjadi sarana untuk membimbing anak menjadi pembaca yang mandiri, menumbuhkan minat baca, dan memiliki kemampuan membaca pemahaman dengan baik. Akan tetap, kenyataan dilapangan menunjukkan bahwa pelajaran Bahasa Indonesia bagi peserta didik dianggap mata pelajaran yang sulit akibat dari perasaan sulit tersebut menyebabkan peserta didik malas untuk membaca dan tidak senang terhadap mata pelajaran Bahasa Indonesia. Berdasarkan observasi dengan Wali kelas pada 10 Desember 2018 di kelas IV A dan IV B di SD Negeri Golo masih belum stabil dan peserta didik masih kurang motivasi belajar pada saat proses pembelajaran peserta didik terlihat bosan, mengantuk, dan bermain dengan teman sebangku, peserta didik aktif dengan kegiatanya sendiri seperti menggambar di buku, berbicara dengan temannya sehingga tidak memperhatikan guru.

Berdasarkan menunjukkan bahwa di SD Negeri Golo, KKM pada mata pelajaran Bahasa Indonesia Kelas IV A dari 26 jumlah Peserta didik sebanyak 10 Peserta didik mendapatkan nilai diatas KKM dan 15 Peserta didik mendapatkan nilai dibawah KKM. Kelas IV B dari 27 jumlah Peserta didik sebanyak 15 Peserta didik mendapatkan nilai diatas KKM dan 12 Peserta didik mendapatkan nilai dibawah KKM. Nilai terendah yaitu 15 dan nilai tertinggi yaitu 90, nilai Peserta didik dalam pelajaran Bahasa Indonesia rendah karena Peserta didik kurang senang dalam poses pembelajaran. Berdasarkan kemampuan membaca Peserta didik di SD Negeri Golo masih termasuk kurang lancar. Dilihat dari masalah di atas disarankan untuk memilih salah satu metode atau media yang cocok sesuai untuk diterapkan pada peserta didik. Maka disini peneliti memilih suatu metode yang di rasakan cocok untuk membantu meningkatkan kemampuan membaca pemahaman kelas IV SD Negeri Golo yaitu Metode Fernald.Dalam upaya memperbaiki kondisi diatas peneliti berkeinginan melakukan penelitian untuk meningkatkan kemampuan membaca pemahaman yang berjudul "pengaruh metode fernald terhadap kemampuan Membaca Peserta didik kelas IV pada mata pelajaran Bahasa Indonesia di SD Negeri Golo tahun ajaran 2019/2020". 
Oleh karenanya analisis metode fernald pada kemampuan membaca pemahaman Mata Pelajaran Bahasa Indonesia Kelas IV SD Negeri Golo harus segera dilaksanakan. Untuk mengatasi permasalahan tersebut, sebuah metode yang diharapkan dapat dimudahkan peserta didik dalam memahami materi pelajaran juga memberikan kesan pengalaman yang bermakna terhadap kemampuan membaca pemahaman. salah satu metode yang dapat digunakan dalam pengajaran membaca pemahaman dengan metode Fernald. Salah satu manfaat dari penggunaan metode multisensori, yaitu memperbaiki respon dan perkembangan anak darisegi penglihatan, pendengaran, serta rabaan. Sebagaimana peserta didik yang membutuhkan pendekatan pengajaran yang mengarah pada kesiapan membaca. Sehingga fungsi mata semakin optimal. Dengan Metode Fernald, anak akan memiliki kesan terhadap bunyi huruf dan bentuk huruf. Tujuan penelitian ini adalah mengetahui adanya pengaruh metode fernald terhadap kemampuan membaca peserta didik kelas IV pada mata pelajaran Bahasa Indonesia di SD Negeri Golo Yogyakarta.

\section{METODE PENELITIAN}

Berdasarkan permasalahan yang diteliti tentang "Pengaruh metode fernald terhadap kemampuan Membaca Peserta didik kelas IV pada mata pelajaran Bahasa Indonesia di SD Negeri Golo tahun ajaran 2019/2020". Peneliti memilih jenis penelitian ini adalah ekperimen dengan Quasi Expreimental Design dengan desain yang digunakan adalah Nonequivalent Control Group Design. Populasi dari penelitian ini adalah seluruh peserta didik kelas IVA dan IVB yang berjumlah 53 Peserta didik. Kelas IVA berjumlah 26 peserta didik sedangkan kelas IVB berjumlah 27 peserta didik SD Negeri Golo. Teknik pengambilan sampel digunakan adalah teknik purposive sampling dan teknik pengumpulan data yang digunakan dalam penelitian ini yaitu tes yang berbentuk soal 25 pilihan Ganda. Uji reabilitas menggunakan rumus Alfa cronbach setelah diperoleh $\mathrm{R}_{\text {hitung }}>\mathrm{R}_{\text {tabel. }}$

\section{HASIL DAN PEMBAHASAN}

Sebelum melaksanakan pretest, soal diujicobakan terlebih dahulu, setelah lulus validasi data, soal tersebut diberikan kepada kelompok ekperimen dan kelompok kontrol. Hasil data pretest kelas ekperimen dan kelas kontrol.

Tabel 1. Deskripsi Data Pretest Kelas Eksperimen dan Kelas Kontrol

\begin{tabular}{ccccc}
\hline Kelas & Mean & Standar Deviasi & Nilai Minimum & Nilai Maksimum \\
\hline Eksperimen & 58.0269 & 11.13235 & 34.78 & 78.26 \\
\hline Kontrol & 47.3426 & 12.37819 & 30.43 & 69.57 \\
\hline
\end{tabular}

Setelah melakukan pretest, peneliti memberikan perlakuan kepada kelompok ekperimen dengan metode Fernald dan kelompok control dengan metode ceramah. Pemberian perlakuan ini di bagi menjadi 4 perlakuan. Setelah masing-masing selesai memberikan perlakuan melaksanakan tes akhir yaitu Posttest hasil data posttest kelas eksperimen dan kelas kontrol, Uji Prasyarat terdiri dari uji normalitas, uji Homogenitas. Bisa lihat tabel 2.

Tabel 2. Deskripsi Data Posttest Kelas Eksperimen dan Kelas Kontrol

\begin{tabular}{ccccc}
\hline Kelas & Mean & Standar Deviasi & Nilai Minimum & Nilai Maksimum \\
\hline Eksperimen & 78.5962 & 9.90816 & 60.87 & 100.00 \\
\hline Kontrol & 64.2522 & 11.20426 & 43.48 & 86.96 \\
\hline
\end{tabular}


Uji Hipotesis digunakan untuk mengetahui ada-tidaknya perbedaan kemampuan membaca pemahaman yaitu peserta didik kelompok ekperimen diajark dengan metode Fernald dan kelompok kontrol diajar dengan model ceramah. Uji hipotesis pada penelitian ini secara ringkas dapat dilihat tabel 3.

Tabel 3. Independent Sampel Test

\begin{tabular}{|c|c|c|c|c|c|c|c|c|c|}
\hline \multirow{4}{*}{$\begin{array}{l}\text { Kemampuan } \\
\text { Membaca } \\
\text { Pemahaman }\end{array}$} & \multirow{2}{*}{$\begin{array}{l}\text { Equal } \\
\text { vanances } \\
\text { assumed }\end{array}$} & \multicolumn{2}{|c|}{$\begin{array}{l}\text { Levene's } \\
\text { Test for } \\
\text { Equalty of } \\
\text { Vanances }\end{array}$} & & \multicolumn{3}{|c|}{ Hest for Equalty of means } & \multicolumn{2}{|c|}{$\begin{array}{l}95 \% \text { Confidence } \\
\text { interval of the } \\
\text { Diffrence }\end{array}$} \\
\hline & & $\mathrm{F}$ & Sig & $\mathrm{t}$ & Df & $\begin{array}{l}\text { Sig (2- } \\
\text { tailed) }\end{array}$ & $\begin{array}{l}\text { Mean } \\
\text { Difference }\end{array}$ & Lower & Upper \\
\hline & $\begin{array}{l}\text { Equal } \\
\text { vanances }\end{array}$ & 209 & 650 & 4.930 & 51 & .000 & 14.34393 & 8.50292 & 20.18494 \\
\hline & assumed & & & 4.942 & 50.642 & .000 & 14.34393 & 8.51565 & 20.17222 \\
\hline
\end{tabular}

Independent sampel Test, dapat digunakan untuk menguji apakah kedua kelompok memiliki rata-rata yang sama dan juga dapat digunakan menguji. Sig 0,650 ternyata Homogen karena nilai lebih dari 0,05 sig. $(0,650)>$ a $(0.05)$ lalu bisa kita liat lagi sig (2tailed) .000 berarti adanya Pengaruh.

Penelitian ini dilakukan bertujuan untuk mengetahui pengaruh Metode Fernald Pemahaman Kemampuan membaca mata pelajaran Bahasa Indonesia kelas IV di SD Negri Golo, penelitian ini menggunakan dua kelas untuk membandingkan kelas yang diberi perlakuan yang berbeda. Pada penelitian ini kelas eksperimen yaitu kelas IV A yang berjumlah 26 Peserta didik dan kelas kontrolnya kelas IV B yang juga berjumlah 27 Peserta didik. Pada penelitian ini terdapat dua variabel yaitu variabel bebasnya (Idenpenden) adalah Metode Fernald dan variabel terikatnya (Dependen) adalah hasil belajar Bahasa Indonesia Peserta didik. Pada penelitian ini bertujuan untuk mengetahui adanya pengaruh Metode Fernald Kemampuan membaca pemahaman mata pelajaran Bahasa Indonesia kelas IV di SD Negeri 1 Golo. Pada saat melaksanakan proses penelitian tahap awal yang dilakukan yaitu Uji coba dengan kelas IV A dan B dengan memberi 25 butir soal Pilihan Ganda dilakukan dengan serentak tujuan mengetahui apakah valid atau tidak Instrumen soalnya dan ternyata ada dua yang tidak valid.

Data yang telah didapati kemudian dianalisis dengan berbagai tahapan, seperti melakukan uji normalitas data untuk mengetahui data tersebut apakah berdistribusi normal atau tidak. Adapun data keseluruhan yang didapati dari perhitungan uji normalitas tersebut semuanya berdistribusi normal, yaitu kelompok eksperimen dengan skewness dan Kurtosis merupakan ukuran untuk melihat apakah data Nilai Bahasa Indonesia didistribusikan secara normal atau tidak.skewness mengukur kemencengan dari data sementara Kurtosis mengukur puncak dari distribusi data. Data dikatakan bersitribusi normal jika mempunyai nilai Skewness dan Kurtosis mendekati nol. Hasil tampilan output SPSS memberikan nilai Skewness Pretest -202 dan Kurtosis -455 kalau Posttest Skewness 080 dan Posttest Kurtosis -409. Hal ini membuktikan bahwa data nilai pretest dan posttest kelompok eksperimen berdistribusi normal. Maka hasilnya untuk kelompok eksperimen, baik nilai pretest maupun posttest berdistribusi normal. Kelompok kontrol nilai Skewness Pretest 218 dan Kurtosis849 kalau Posttest Skewness 003 dan Kurtosis -501 hasilnya bahwa data kelas B berdistribusi normal. Data yang telah dinyatakan normal dan homogen maka dapat dilakukan analisis terakhir.Analisis terakhir yang dilakukan adalah uji hipotesis dengan uji Independet Sampel Test, thitung $>$ ttabel maka $\mathrm{H}_{0}$ ditolak dan $\mathrm{H}_{1}$ diterima, sedangkan jika thitung $<\mathrm{t}_{\text {tabel }}$ maka $\mathrm{H} 0$ diterima dan $\mathrm{H} 1$ ditolak.

Penelitian ini memberikan pengaruh positif terhadap hasil belajar dab motivasi belajar dengan menggunakan metode fernald.Hal ini tersebut dikarenakan dengan metode yang diberikan akan meningkatkan keaktifan peserta didik dalam belajar, dan membuat 
semangat peserta didik untuk belajar sehingga hasil belajarnya meningkat. Penelitian ini pernah dilakukan oleh Ratih Ratnasari dan Ehan tahun 2017 berjudul jurnal adalah pengaruh metode fernald terhadap kemampuan membaca permulaan huruf awas peserta didik low vision. Proses pembelajaran menggunakan metode Fernald membutuhkan komunikasi atau cara penyampaian yang baik dengan Peserta didik agar dapat mudah dipahami maksud dan langkah-langkah pembelajaran yang diberikan. Komponen-komponen dalam metode Fernald adalah penyajian materi, Kelompok, Diskusi, Membaca secara bersama temen kelompok dan penghargaan kelompok. Kegiatan pembelajaran dimulai dengan mengorientasikan Peserta didik pada sebuah permasalahan kemampuan membaca melihat kemampuan awal Peserta didik dengan pemberian apersepsi. Kemudian Peserta didik diberikan penjelasan sedikit mengenai materi Cerita fiksi lalu membentu dalam kelompok dan memberikan Buku Tematik mengerjakan bersama-sama dengan anggota kelompoknya. Lalu guru memberikan kuis berupa pertanyaan secara langsung, Setiap anggota kelompok yang bisa menjawab terlebih dahulu mengangkat tangan. Setelah itu setiap kelompok maju ke depan kelas sambil membaca menyaring agar semua temen kelompok juga ikut bersamaan membaca. Proses pembelajaran dilakukan secara berkelompok untuk menunjang kerja sama Peserta didik dalam menyelesaikan sebuah permasalah. Proses pembelajaran ini merupakan pembelajaran yang secara sadar dan sengaja dilakukan untuk mengembangkan interaksi saling asuh antar Peserta didik untuk menghindari kesalahpahaman dimana Peserta didik akan lebih mudah memahami membaca dengan saling berdiskusi dan bertukar pikiran dalam menyelesaikan permasalahan. Berdasarkan hal tersebut dapat dikatakan bahwa pelaksanaan pembelajaran ini dapat memberikan pengaruh dalam meningkatkan hasil belajar kemampuan membaca pemahaman kepada Peserta didik. Proses pembelajaran dapat berlangsung secara kondusif dan menyenangkan apabila dipersiapkan dengan matang serta penyampaian materi dapat disampaikan menggunakan kalimat yang mudah untuk dipahami oleh Peserta didik

\section{SIMPULAN}

Kelompok Eksperimen hasil Pretest mendapatakan nilai rata-rata (mean) 58.0269 dan kelompok Kontrol mendapatkan nilai rata-rata (mean) 47.3426. Sesudah diberi perlakuan hasil post-test didapatkan kelompok Eksperimen mendapatkan nilai rata-rata (mean) 78.5962 dan kelompok Kontrol mendapatkan nilai rata-rata (mean) 64.2522. Jika data penelitian sudah normal dan homogen dalam uji Normalitas dan homogenitas. selanjutnya Uji Independet sampel t-test dengan bantuan Software SPSS 21.0 diketahui p yaitu 0,000 dengan taraf signitikan 0,05 sehingga dapat dituliskan 0,000 < 0,05 yang menunjukan adanya peningkatan nilai rata-rata peserta didik. Menentukan Hipotesis yaitu thitung $>$ t tabel dan dfnya 51 sehingga dapat ditentukan $4.930>.650$ yang menunjukan bahwa Ho ditolak yang artinya ada Pengaruh metode Fernald kemampuan membaca pemahaman.

\section{DAFTAR PUSTAKA}

Dalman. (2014). Keterampilan Membaca. Jakarta: Rajawali perss.

Faisal, \& dkk. (2009). Kajian Bahasa Indonesia SD. Jakarta: Direktoral Jenderal Perguruan Tinggi Departemen Pendidikan Nasional.

Nurhadi. (2016). Teknik Membaca. Jakarta: Bumi Aksara.

Samsu, S. \&. (2012). Strategis dan Teknik Pembelajaran Membaca. Yogyakarta: Graha Ilmu.

Tarigan, H. (2008). Membaca Sebagai Suatu Keterampilan Berbahasa. Bandung: Angkasa. 